\title{
Influence of Heat Treatment and Composition Variations on Microstructure, Hardness, and Wear Resistance of C 18000 Copper Alloy
}

\author{
Ramon Osorio-Galicia, ${ }^{1}$ Carlos Gomez-Garcia, ${ }^{1}$ \\ Miguel Angel Alcantara, ${ }^{2}$ and Andres Herrera-Vazquez ${ }^{1}$ \\ ${ }^{1}$ FES Cuautitlan, Universidad Nacional Autonoma de Mexico, Km 2.5 Carretera Cuautitlan-Teoloyucan, San Sebastian Xhala, \\ Cuautitlan Izcalli, 54714 MEX, Mexico \\ ${ }^{2}$ CIATEQ (Advanced Technology Center) Aeronautical Materials Group, Avenue Manantiales No. 23-A, 76246 Qro, \\ Parque Industrial Bernardo Quintana, El Marquez Qro, Mexico
}

Correspondence should be addressed to Andres Herrera-Vazquez, aherrerv@unam.mx

Received 19 January 2012; Accepted 7 February 2012

Academic Editors: B. Chan and F. Liu

Copyright ( 2012 Ramon Osorio-Galicia et al. This is an open access article distributed under the Creative Commons Attribution License, which permits unrestricted use, distribution, and reproduction in any medium, provided the original work is properly cited.

The hardness and wear behavior properties of two C 18000 copper alloys with variations in Ni, Si, and Cr concentrations, both within the range of $\mathrm{C} 18000$ chemical analysis standard, were studied after the alloy samples had been prepared by melting and casting in sand molds and then heat-treated in solution using two-stage aging for different heating time periods. The results obtained from sample sets of the aforementioned two alloys, $\mathrm{C}_{0}$ and $\mathrm{C}_{1}$, show that the alloy $\mathrm{C}_{1}$, with slightly higher $\mathrm{Si}$ and $\mathrm{Ni}$ and lower $\mathrm{Cr}$ concentrations than the alloy $\mathrm{C}_{0}$, produced significantly higher hardness values and wear resistance than the alloy $\mathrm{C}_{0}$. Optical and electron microscopy microstructure studies of representative samples revealed a copper matrix containing nickel and silicon in solution and precipitates of chromium and nickel silicides. By studying the wear surfaces and debris of the former samples with electron microscopy, different types of wear mechanisms including adhesive, abrasive, oxidation, and repeated-cycle deformation were found. The wear behavior was expressed as mass weight loss, which correspondingly shows a typical inverse relationship with the hardness values for both the $\mathrm{C}_{0}$ and $\mathrm{C}_{1}$ alloy groups.

\section{Introduction}

A search of the literature for studies related to the wear behavior and hardness of C 18000 copper alloys after heat treatment was conducted; however, no significant publications were found in this field for these particular alloys. Nevertheless, there has been continuous work on copper alloys as well as other materials, such as $\mathrm{Cu}-\mathrm{Be}$ alloys for engineering applications to reduce health risks and production costs, but these studies mostly focus on the functional requirements for each case. In addition, bronzes, such as aged cast C 95200 and C 95300 aluminum bronzes, are widely used in several tribological applications, improving wear behavior, friction coefficients, and favorable changes in microstructure [1]. Similarly, the tribological behavior of two $\mathrm{Cu}-\mathrm{Be}$ alloys shows a transition in the wear mechanism from metallic wear to tribo-oxidative wear as the applied load is increased [2]. $\mathrm{Cu}_{\mathrm{ss}}$-toughened silicide alloys exhibit excellent wear resistance and a low friction coefficient at room temperature under dry sliding wear test conditions with hardened $0.45 \% \mathrm{C}$ carbon steel as the sliding-mating counterpart [3]. At a constant current density, the wear rate of $\mathrm{Cu}-\mathrm{Cr}-\mathrm{Zr}$ alloy decreases with aging temperature and reaches a minimum at $500^{\circ} \mathrm{C}$; it then increases with further increasing aging temperature. The improvement in wear resistance is due to the formation of fine, dispersive, and coherent precipitates within the matrix [4]. The wear rate of this alloy also increases with electrical current, and sliding speed, adhesive wear, abrasive wear, and arc erosion are the dominant mechanisms during the electrical sliding 
processes for $\mathrm{Cu}-\mathrm{Ag}-\mathrm{Cr}[5,6]$. The experimental results for a commercial aluminum bronze alloy $(\mathrm{Cu}-10 \% \mathrm{Al}-4 \% \mathrm{Fe})$ produced by hot rolling and subjected to equal channel angular extrusion (ECAE) at a high temperature, showed that grain size decreased and the second phase was rearranged; in addition, the hardness and the strength increased after ECAE, and adhesive wear was the primary wear mechanisms for the specimen without ECAE under dry sliding, whereas abrasive wear was the primary wear mechanism after two passes of ECAE [7]. The tribological behavior of dilute solid solution $\mathrm{Cu}-\mathrm{Al}$ alloys in sliding contact with sapphire and D2 steel was investigated; The wear rate of the solid solution $\mathrm{Cu}-\mathrm{Al}$ alloys was found to increase with increasing aluminum content and high aluminum content were found to promote planar slip, adhesive wear and the formation of metallic wear debris [8]. The hardness of aged $\mathrm{Cu}-15 \mathrm{Ni}-8 \mathrm{Sn}$ specimens was found to increase initially with the aging time and then decrease. The best reported wear resistance of the alloy tested corresponded to the maximum value of hardness after aging for $120 \mathrm{~min}$ [9].

In the present work, several sample specimens of two C 18000 copper alloys were melted and heat-treated under different aging regimens to study the effect of slight variations in chemical composition and heat treatment on microstructure, hardness, and wear resistance.

\section{Materials and Experimental Procedures}

2.1. Melted Materials. Two copper samples of the C 18000 alloy were studied: $\mathrm{C}_{0}$ group $(2.22 \% \mathrm{Ni}, 0.57 \% \mathrm{Si}, 0.73 \%$ $\mathrm{Cr}, 0.084 \% \mathrm{Fe})$ and $\mathrm{C}_{1}$ group $(2.57 \% \mathrm{Ni}, 0.70 \% \mathrm{Si}, 0.30 \%$ $\mathrm{Cr},<0.01 \% \mathrm{Fe}$ ). The two alloys were melted in an induction heating furnace and poured into silica sand molds to obtain plates with the dimensions $10 \mathrm{~cm} \times 15 \mathrm{~cm} \times 15 \mathrm{~cm}$.

2.2. Heat Treatment. A set of 16 samples with the dimensions $1.8 \mathrm{~cm} \times 2.0 \mathrm{~cm} \times 1.0 \mathrm{~cm}$ of $\mathrm{C}_{0}$ and $\mathrm{C}_{1}$ alloys were prepared for heat treatment. The solution treatment temperature was held at $1223 \mathrm{~K}$ for 3 hours; the first aging treatment temperature was $823 \mathrm{~K}$ and the second aging treatment temperature was $703 \mathrm{~K}$. The samples were numbered from 1 to 8 , denoted as having been treated and classified as either a $\mathrm{C}_{0}$ or $\mathrm{C}_{1}$ alloy. The samples were classified as follows: (1) received as cast, (2) tempered, (3) 3-hour aging, (4) 5hour aging, (5) two-stage aging treatment: 3-hour aging, then cooled to room temperature with a second 3 hour aging treatment, (6) two-step aging treatment: 3-hour aging, then cooled to room temperature with a second 5-hour aging treatment, (7) two-step aging treatment: 5-hour aging, then cooled to room temperature with a second 3-hour aging treatment (8) two-step aged treatment: 5-hour aging, then cooled to room temperature with a second 5-hour aging treatment.

2.3. Metallography. All of the samples were metallographically studied using an MG Olympus Optical microscope model 502980 after being sectioned from as-cast and heattreated bars, polished, and etched with potasic bichromate,



FIGURE 1: Hardness RB versus aging heat treatment time for $\mathrm{C}_{0}$ and $\mathrm{C}_{1}$ copper alloys.

according to standard optical microscopy procedures [10]. The wear surfaces and wear debris of selected samples were characterized using a scanning electron microscope (SEM) equipped with an energy dispersive X-ray (EDX) microanalysis system.

2.4. Wear Testing. An electronic analytical weighing instrument with a precision of $0.0001 \mathrm{~g}$ was used to obtain the weight loss for each sample tested.

Wear tests were performed in a disc-shaped device. The pin-on-disc machine employed is a custom-built apparatus used to test materials in sliding contact within a range of loads and speeds [11]. The "pins" used were C18000 samples and the "disc" was made of 48 HRc stainless steel. In pinon-disc tribometry, a pin is loaded with a precisely known weight and the disc is rotated. The specimens were subjected to wear cycles on a disc at $2000 \mathrm{rpm}$ and a load of $4.9 \mathrm{~N}$ with a constant water flow for $25 \mathrm{~min}$ each; the contact area was always $1.8 \mathrm{~cm} \times 2.0 \mathrm{~cm}$. For selected samples, cylindrical pin specimens $6.35 \mathrm{~mm}$ in diameter and $10 \mathrm{~mm}$ in length were tested for dry sliding wear to study the wear surfaces.

2.5. Hardness. Rockwell " $\mathrm{B}$ " hardness (HRB) values were obtained with a sphere penetrator of hardened steel 1/16 of an inch in diameter, preloaded with $98.1 \mathrm{~N}\left(10 \mathrm{~kg}_{\mathrm{f}}\right)$ for $10 \mathrm{sec}$, and loaded with $981 \mathrm{~N}\left(100 \mathrm{~kg}_{\mathrm{f}}\right)$ for $10 \mathrm{sec}$. The reported values are the averages of at least six measurements for each sample.

\section{Results}

The mass losses during wear testing and the Rockwell B hardness variations for different aging time periods in each treated alloy are shown in Figure 1 for $\mathrm{C}_{0}$ and Figure 2 for 


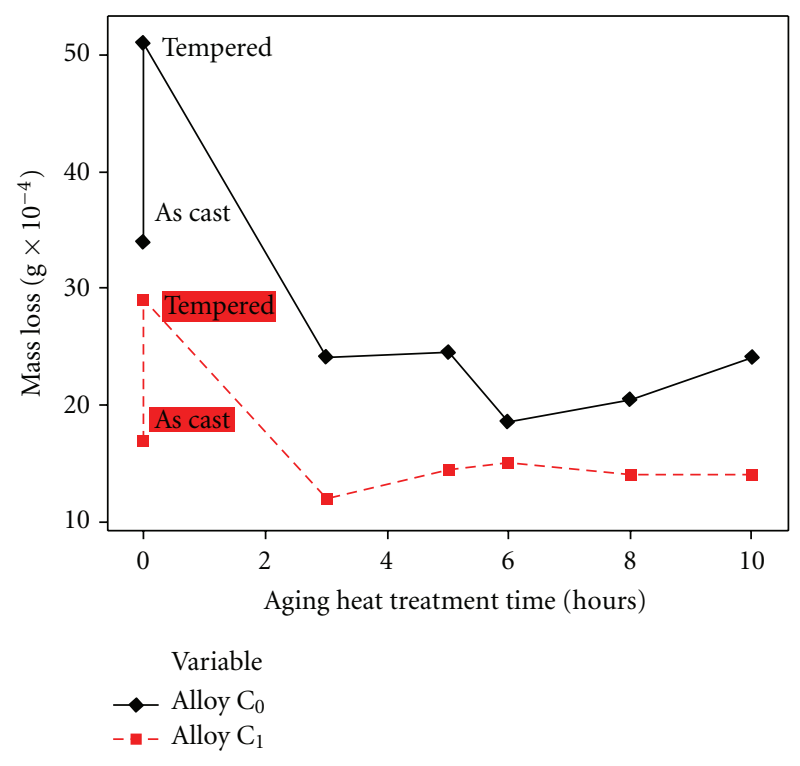

Figure 2: Mass loss $\left(\mathrm{g} \times 10^{-4}\right)$ versus aging heat treatment time in hours.

$\mathrm{C}_{1}$ alloys; the graph includes hardness values for as-cast and solution-treated samples as a reference for the initial conditions in both alloys.

Figure 2 shows the wear mass loss values as a function of aging treatment time for both $\mathrm{C}_{0}$ and $\mathrm{C}_{1}$ alloys.

The $\mathrm{C}_{1}$ alloy samples exhibited higher hardness values than the alloy $\mathrm{C}_{0}$ samples for all conditions. The graphs show a clear expected inverse correspondence relationship between the hardness and the mass losses. The as-cast samples exhibited intermediate hardness values around 22 $\mathrm{HRb}$ for $\mathrm{C}_{0}$ and $65 \mathrm{HRb}$ for $\mathrm{C}_{1}$.

Figures 3(a) and 3(b) show a representative optical micrograph of samples $\mathrm{C}_{0}$ ( $8 \mathrm{hr}$ aging) and $\mathrm{C}_{1}$ ( $3 \mathrm{hrs}$ aging) in which different grain morphologies were observed due to marked grain boundaries and different precipitates; Figure 3(b) shows possible slip bands in one grain. Similarly, higher wear resistance was observed for sample 3 in alloy group $\mathrm{C}_{1}$ after 3 hours of aging; its rate of mass loss during the wear resistance test was $12 \times 10^{-4} \mathrm{~g}$ which was lower than the $18.5 \times 10^{-4} \mathrm{~g}$ rate obtained for sample 6 of alloy group $\mathrm{C}_{0}$ which had been aging $6 \mathrm{hrs}$.

The SEM micrograph in Figure 4 shows a black area where silicide precipitates of chromium and nickel occurred in the microstructure of the copper alloy, as confirmed by EDS analysis shown in Figure 5.

The alloying elements exerted a hardening effect on the copper matrix when the $\mathrm{C}_{0}$ and $\mathrm{C}_{1}$ alloys were aged by heat treating for different time periods, although the $\mathrm{C}_{1}$ alloy resulted in a higher hardness values in all treatment conditions compared with $\mathrm{C}_{0}$.

The wear surfaces of both alloys subjected to different heat treatment conditions are shown in Figures 6 and $7(\mathrm{a})$ for $\mathrm{C}_{0}$ alloy aged 3 and 5 hours, X2500. Figure 7(b), X10000, shows microgrooves produced by the plowing action of the wear debris. Figure 8(a), X1000, and Figure 8(b), X1000, show the wear surface of the $\mathrm{C}_{0}$ alloy; wear steps are observed on the surface of the specimen; carbon resulted from an impurity from the machine disc. Figure 9(a), X1000, and Figure 9(b), X5000, show sample $C_{1}$ after tempering; the appearance of the worn surface is characteristic of the abrasive and adhesive wear mechanisms. The hardness of the steel disk is higher $(48 \mathrm{HRc})$ than that corresponding to the hardness of the C18000 pin alloy, and so the asperities on the surface can penetrate the copper alloy. Figure 10, X2500, shows sample $\mathrm{C}_{1}$ after aging for 3 hours. The repeated sliding contact probably resulted in the fracture of the oxide film which formed between the interfaces and the detached oxide debris since the hard abrasive also caused abrasive wear.

\section{Discussion}

The present study was motivated by a clear inconsistent wearing performance of different batches of C18000 copper alloy moulds in industrial applications that exhibited significant differences in hardness and wear resistances; such batches did comply with the standard [12] chemical composition and heat treatment. This study is oriented to confirming and explaining such observations by testing wear resistance and hardness of two compositions of the C1800 copper alloy.

With regard to the physical metallurgy of this alloy, some elements have a varying degree of solid solubility in copper, which changes as the temperature increases. This makes it possible to form the so-called age- or precipitation-hardened alloys.

It is well known that, by reheating to a selected lower temperature for various periods of time, specific metallic compounds in solution could precipitate out of its solid solution. The effect of this treatment serves two purposes: first, the alloying elements precipitated out of solid solution form discrete particles, which increase the strength and hardness (from 5.05 to $96.35 \mathrm{HRb}$ in sample $\mathrm{C}_{1}$ ) by interfering with the normal mode of physical deformation of the metal under stress; second, an increase in the electrical conductivity of the alloy through the effective removal of alloying elements in solid solution from the copper matrix, as is the case for copper alloys containing silicon and one or more silicideforming elements, specifically chromium, cobalt, and nickel. In accordance with a previous study [13], improved hardness was achieved by heating the alloy to a temperature within the range of $978 \mathrm{~K}$ to $1248 \mathrm{~K}$ and subsequently quenching the alloy to freeze the bulk of the alloying elements in solid solution. After quenching, this alloy was aged at a temperature within the range of $523 \mathrm{~K}$ to $873 \mathrm{~K}$ to precipitate the metallic silicides, resulting in an increase in hardness [13].

The former statements are in agreement with our results as can be seen in Figures 4 and 5, which show the silicide precipitates and are confirmed by EDS analysis of representative samples, in which hardness was influenced significantly for $\mathrm{C}_{1}$ alloy, which was solution-treated and aged for three hours (reaching $96.35 \mathrm{HRb}$ ). For sample $\mathrm{C}_{0}$ alloy, hardness was also improved from a value of $22.83 \mathrm{HRb}$ as cast to $56.03 \mathrm{HRb}$, after $3-5$ hours of heat-treatment aging. 


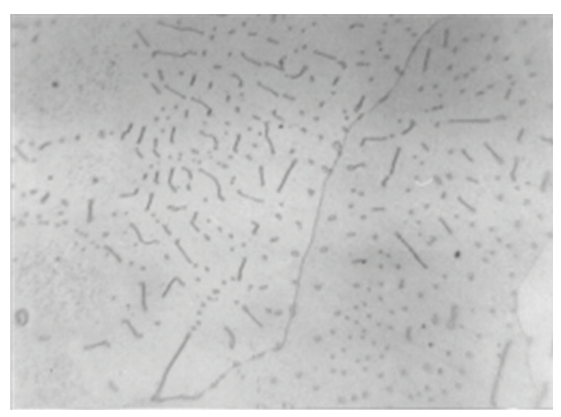

(a)

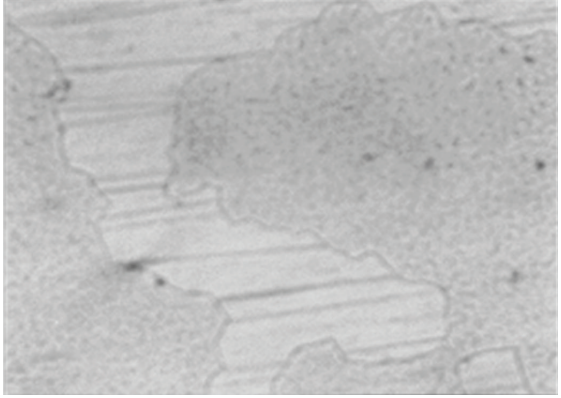

(b)

Figure 3: Microstructure of samples, (a) $\mathrm{C}_{0} 400 \mathrm{X}$ and (b) $\mathrm{C}_{1} 280 \mathrm{X}$.

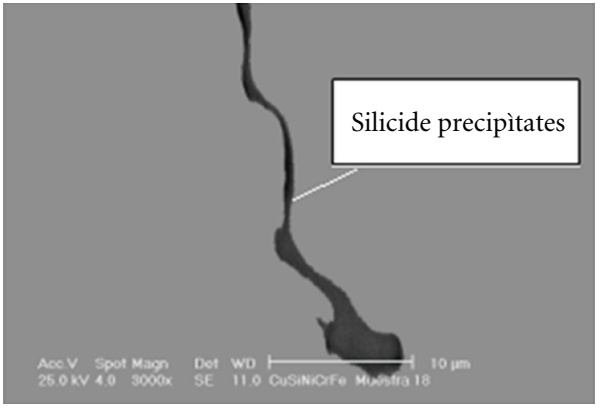

FIGURE 4: SEM micrograph of sample $C_{1}$ showing a black boundary grain where silicides precipitates of chromium and nickel occurred.

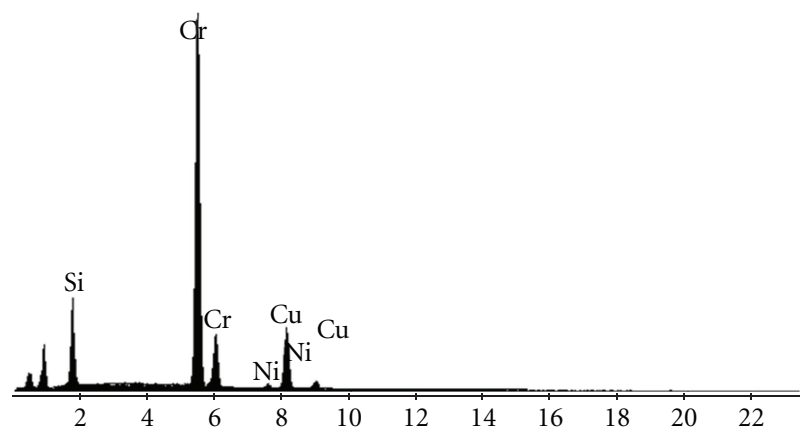

FIGURE 5: EDS analysis of boundary grain of sample $\mathrm{C}_{1}$.

In Figure 6, except in abrasive situations and some sliding situations involving soft materials and very rough surfaces, a single wear mechanism is observed to become less significant as wear process progresses, which is generally attributed to changes that take place due to wear and the emergence of other mechanisms that contribute to the reduction of singlecycle wear and the appearance of average junction stress and associated penetration, increased conformity of surfaces, and strain hardening.

Figures 7(a) and 7(b) at higher magnifications show an indication of the repeated-cycles deformation mechanism, which appears to become the dominant wear mechanism. Abrasive wear deformation was caused by hard particles or hard protuberances [14], as shown in Figure 8(b). In

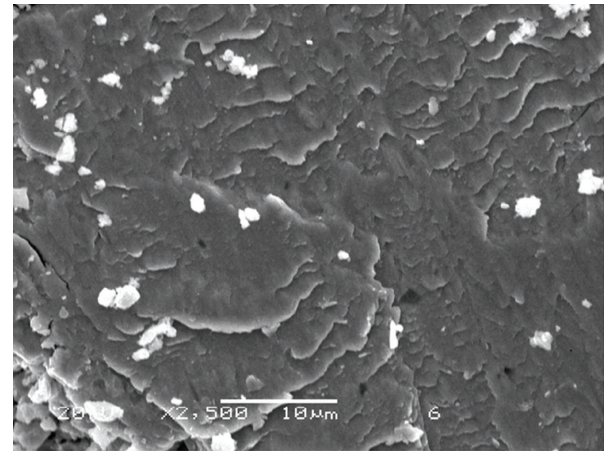

Figure 6: Morphology of the worn surface of sample $\mathrm{C}_{0}$.

Figures 9(a) and 9(b), the dominant wear mechanisms are of the abrasive and adhesive types; the former can be attributed to the presence of high shear stresses and low normal stresses. It is believed that the hard asperities on the disk surface can penetrate the copper alloy pin during sliding.

In Figure 10 it can be seen that the debris assumes a platelike shape; EDS analysis shows that the wear debris is composed mainly of metallic copper-nickel fragments, which were detached from the pin sample during wear testing.

Regarding the influence of slight variations in chemical composition on the hardness and wear resistance of the C18000 Copper alloy, there are different mechanisms to explain such observed change in properties during the tests carried out in this work.

The nominal $\mathrm{C} 18000 \mathrm{Cu}$ alloy composition range is $2.0 \%$ to $3.0 \%$ nickel, $0.4 \%$ to $0.8 \%$ silicon, and $0.1 \%$ to $0.5 \%$ chromium [12]. In this composition range, Si content only covers part of the concentrations required for stoichiometric formation of $\mathrm{Cr}$ and $\mathrm{Ni}$ silicides to form $\mathrm{Ni}_{2} \mathrm{Si}$ and $\mathrm{CrSi}_{2}$, so an increase in $\mathrm{Si}$ and decrease in $\mathrm{Cr}$ content within the said composition range will result in different mechanisms for the hardness increase observed in our case. Also, as Cr decreases (parallel to Si increase), hardness increase might be enhanced by the extra Si available for solid solution and nickel silicides formation as hardening mechanisms, especially considering the $\mathrm{Si}$ solid solution in $\mathrm{Cu}$ for solution and precipitation hardening mechanisms. As observed in our case, the $\mathrm{C}_{1}$ alloy with more Si also exhibited higher hardness than the $C_{0}$ in 


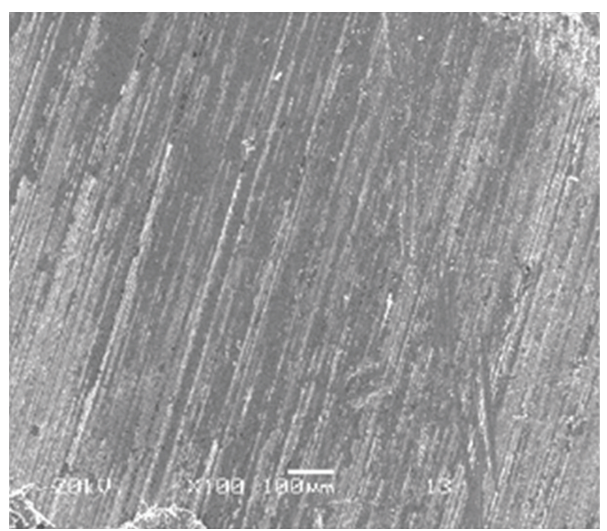

(a)

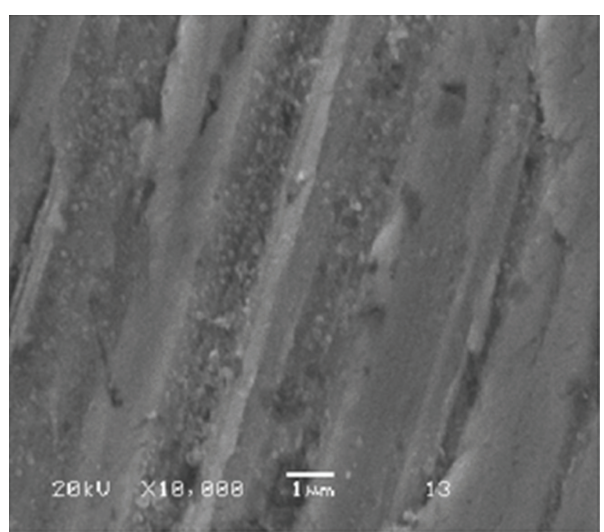

(b)

Figure 7: (a) Numerous delaminated sheets at the worn surface; (b) the worn surface, 10000x magnification, of $\mathrm{C}_{0}$ sample.

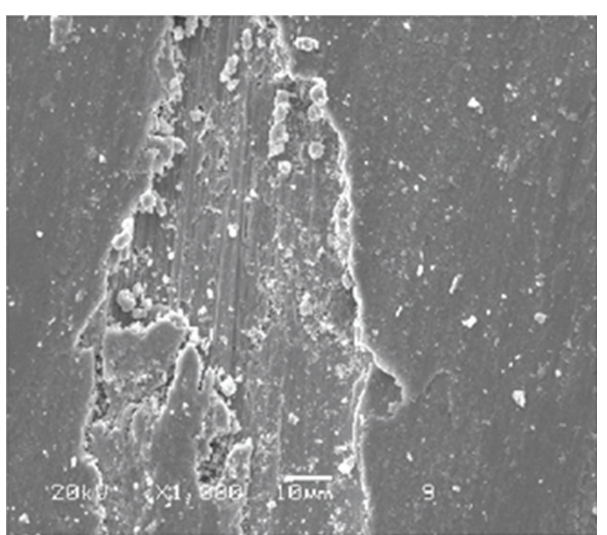

(a)

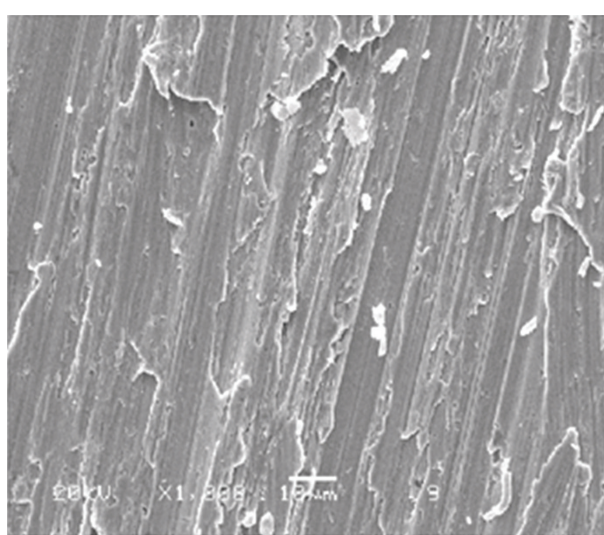

(b)

Figure 8: (a) The morphology of the worn surface of sample $\mathrm{C}_{0}$; (b) the worn surface showing the adhesive wear mechanism of sample $\mathrm{C}_{0}$.

the full solubility condition after a $1223 \mathrm{~K}, 3$-hour solubility treatment.

From the obtained results we suggest that one, or a combination of these mechanisms explain the increase in hardness and wear resistance observed when silicon content is increased. The increase in hardness as aging time increases, which is a general trend in these alloys, is associated with fine precipitate dispersion [4]; in this case the observed fine silicide distribution having more $\mathrm{Si}$ available operates to increase hardness during the aging treatment. Electron microscope images in Figure 4 show these dispersive fine precipitates.

The results obtained in this work are relevant in the context of the selection of high wearing resistance copper alloys, and in particular for the C18000 copper alloy when used in tribological applications as slight variation in chemical composition within the standard of the C18000 copper alloy might produce significant property deviations as shown in the tests carried out in the present work. Further work has to be done on this alloy as apparently the range of each individual chemical element concentration in the standard [12] is too wide for achieving uniform properties.

\section{Conclusions}

The well-known metallurgical behavior regarding hardness increase and wear resistance improvement obtained from precipitation of chromium and nickel silicides in a hardening treatment of a C 18000 copper alloy were confirmed in this work. Nevertheless, it was observed that a slight increase in $\mathrm{Si}$ and $\mathrm{Ni}$ and a slight decrease in $\mathrm{Cr}$ content in $\mathrm{C}_{1}$ alloy produced a significant increase in hardness and wear resistance of $\mathrm{C}_{1}$ compared with $\mathrm{C}_{0}$, both within the nominal C18000 Copper alloy composition and having the same heat treatment history. Examination of the wear surfaces of the alloys mainly showed the presence of adhesive and abrasive wear mechanisms.

\section{Acknowledgments}

The authors thank the Universidad Nacional Autonoma de Mexico, FES-Cuautitlan, and the Centro de Investigacion y Asistencia Tecnica del Estado de Queretaro for the provision of facilities used to do this study and particularly Alicia del Real from CFATA-UNAM for her support in electron 


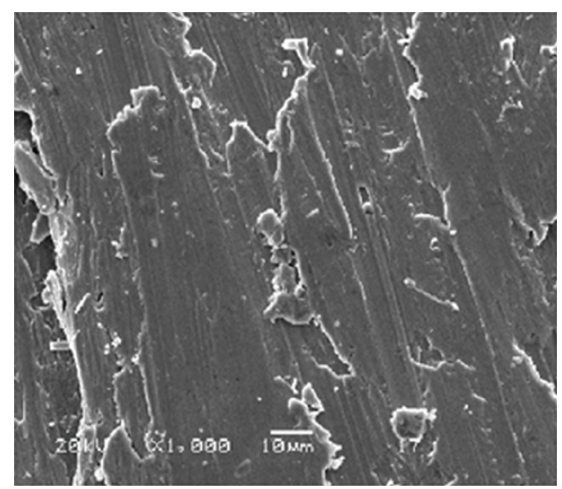

(a)

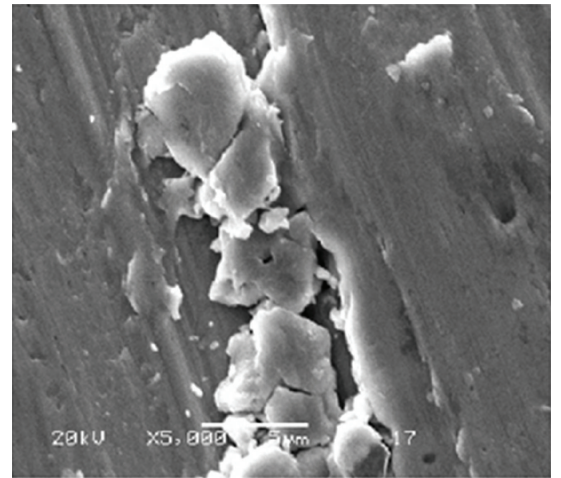

(b)

FIGURE 9: (a) The morphology of the worn surface showing the adhesive wear mechanism; (b) the worn surface showing the abrasive wear mechanism of sample $\mathrm{C}_{1}$.



(a)

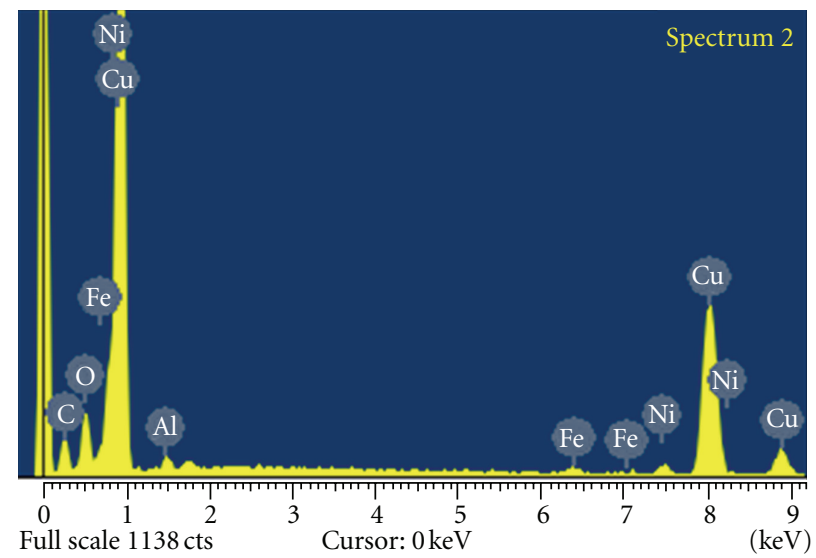

(b)

Figure 10: (a) Wear debris of sample $\mathrm{C}_{1}$; (b) EDS analysis of sample $\mathrm{C}_{1}$.

microscope and Mr. D. Stauffer for his help in the English version of this work.

\section{References}

[1] Y. Altunpak and Mustafa Y., "The effect of aging heat treatment on the sliding wear behaviour of $\mathrm{Cu}-\mathrm{Al}-\mathrm{Fe}$ alloys," Materials and Design, vol. 30, no. 3, pp. 878-884, 2009.

[2] G. Straffelini, L. Maines, M. Pellizzari, and P. Scardi, "Dry sliding wear of Cu-Be alloys," Wear, vol. 259, no. 1-6, pp. 506511, 2005.

[3] Y. X. Yin and H. M. Wang, "Microstructure and wear resistance of Cuss-toughened $\mathrm{Cr}_{5} \mathrm{Si}_{3} / \mathrm{CrSi}$ metal silicide alloys," Journal of Materials Research, vol. 20, no. 5, pp. 1122-1130, 2005.

[4] J. P. Tu, W. X. Qi, Y. Z. Yang et al., "Effect of aging treatment on the electrical sliding wear behavior of $\mathrm{Cu}-\mathrm{Cr}-\mathrm{Zr}$ alloy," Wear, vol. 249, no. 10-11, pp. 1021-1027, 2001.

[5] S. G. Jia, P. Liu, F. Z. Ren, B. H. Tian, M. S. Zheng, and G. S. Zhou, "Sliding wear behavior of copper alloy contact wire against copper-based strip for high-speed electrified railways," Wear, vol. 262, no. 7-8, pp. 772-777, 2007.
[6] S. G. Jia, M. S. Zheng, P. Liu, F. Z. Ren, B. H. Tian, and G. S. Zhou, "Wear behavior of Cu-Ag-Cr alloy wire under electrical sliding," Materials Science and Engineering A, vol. 428, no. 1-2, p. 358, 2006.

[7] L. L. Gao and X. H. Cheng, "Microstructure and dry sliding wear behavior of $\mathrm{Cu}-10 \% \mathrm{Al}-4 \% \mathrm{Fe}$ alloy produced by equal channel angular extrusion,” Wear, vol. 265, pp. 986-991, 2008.

[8] R. A. Poggie and J. J. Wert, "The role of oxidation in the friction and wear behavior of solid solution $\mathrm{Cu}-\mathrm{Al}$ alloys in reciprocating sliding contact with sapphire and D2 tool steel," Wear, vol. 156, no. 2, pp. 315-326, 1992.

[9] S. Z. Zhang, B. H. Jiang, and W. J. Ding, "Wear of Cu-15Ni8Sn spinodal alloy," Wear, vol. 264, no. 3-4, pp. 199-203, 2008.

[10] ASM International Metals Handbook, vol. 9, 2005.

[11] ASTM, Designation G99-95a Standard Test Method for Wear Testing With a Pin-On-Disk Apparatus, 2000.

[12] Annual Book of ASTM Standards, vol. 02.01 of Section 2, 1990.

[13] W. Walter, E. Ingerson, and F. Quentin, "Copper-nickelsilicon-chromium alloy having improved electrical conductivity," USA Patent 4260435, 1981.

[14] R. G. Bayer, Mechanical wear fundamentals and testing, Marcel Dekker, New York, NY, USA, 2nd edition, 2004. 

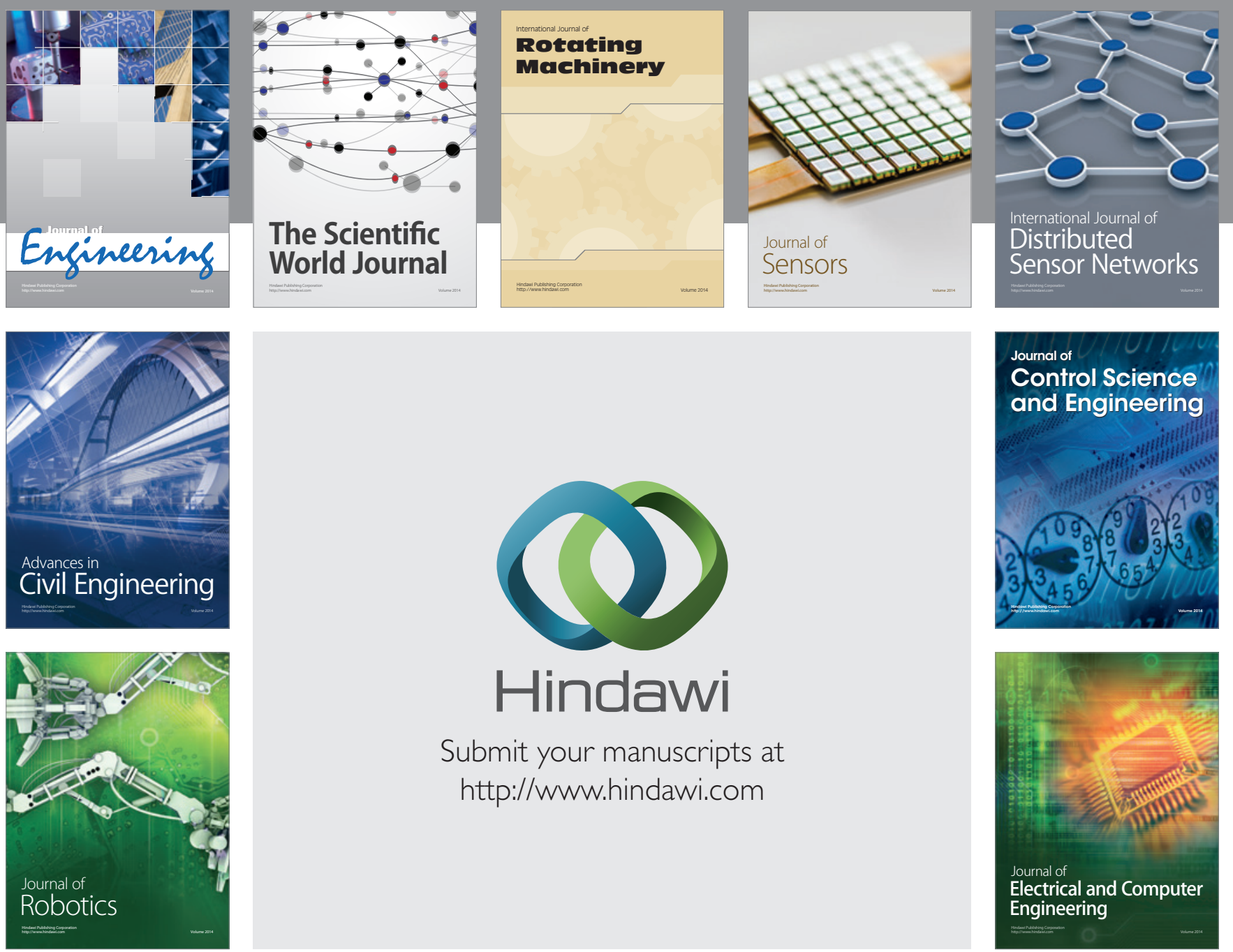

Submit your manuscripts at

http://www.hindawi.com
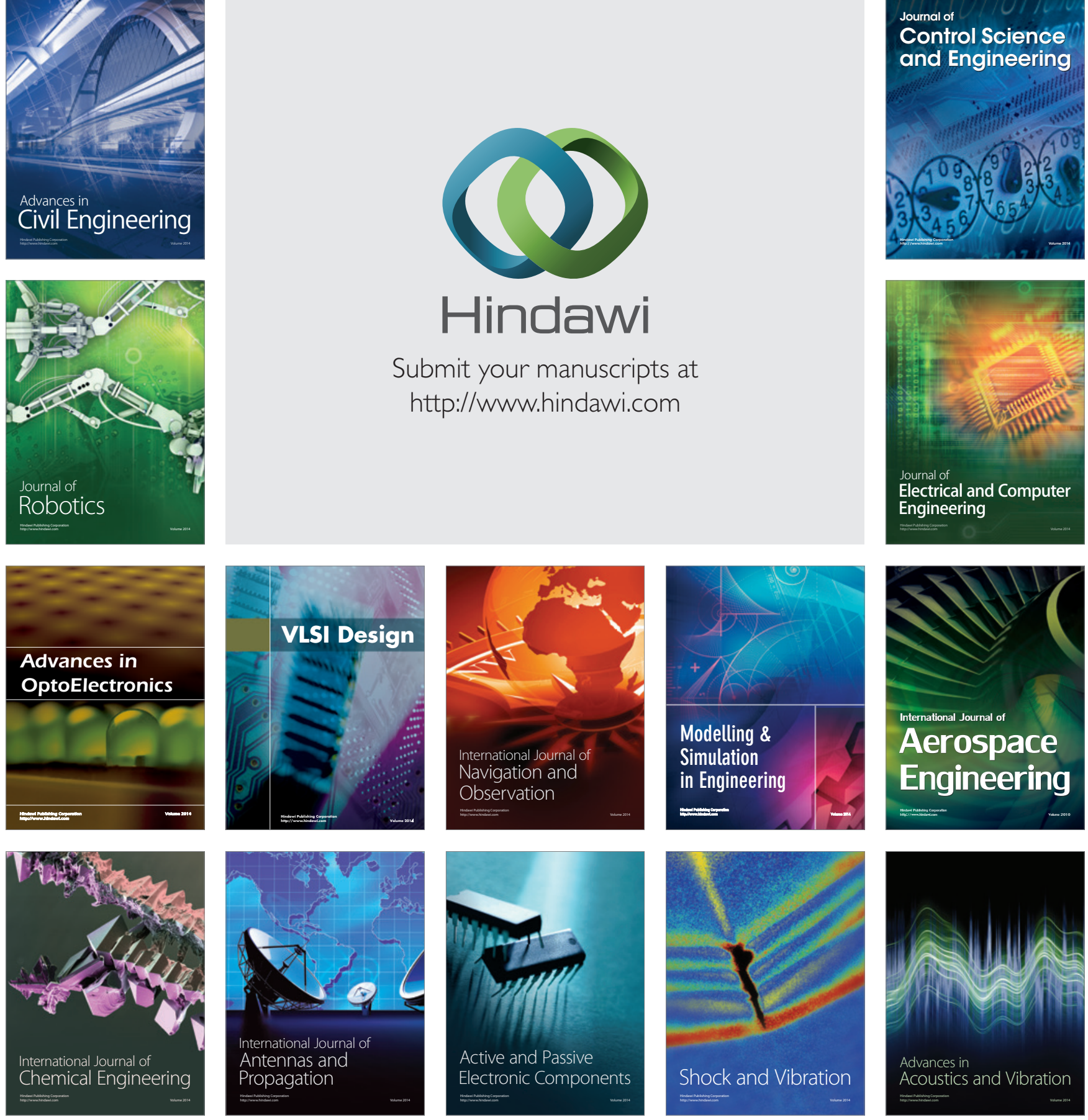